\title{
OS BENEFÍCIOS DA UTILIZAÇÃO DA ESTRATÉGIA TAPERING NA REDUÇÃO DAS CARGAS DE LAMINAÇÃO NAS PONTAS DA TIRA EM LAMINADORES STECKEL*
}

\author{
Altair Lúcio de Souza ${ }^{1}$ \\ Jacson Morais Borges ${ }^{2}$ \\ Joao Júnio Pereira Lino ${ }^{3}$ \\ John Hanna Frenn ${ }^{4}$ \\ Maurício Martins Pereira 5 \\ Willy Schuwarten Júnior ${ }^{6}$
}

\begin{abstract}
Resumo
A laminação de tiras a quente com laminadores Steckel tem como característica um perfil de temperatura mais baixa nas pontas sendo este um dos motivos que geram cargas de laminação muito mais altas nesta região. A carga de laminação elevada tem como consequência no processo a geração de desvios de planicidade e o alto risco de rompimento do material nos passes finais de laminação. Este trabalho tem como objetivo demonstrar os benefícios da utilização da estratégia de Tapering para a laminação de tiras de espessura fina em laminador Steckel. Foi feita a comparação das cargas de laminação do material laminado e o acompanhamento dos resultados de planicidade obtidos antes e depois da implantação desta função. Ao fim do trabalho verificamos que a estratégia de Tapering é essencial para o processamento de materiais finos com laminadores Steckel.
\end{abstract}

Palavras-chave: Laminador steckel; Tapering; Laminação a quente; Cargas de laminação.

\section{THE BENEFITS OF USING THE TAPERING STRATEGY FOR ROLLING LOAD REDUCTION AT THE HEAD AND TAIL ENDS AT STECKEL MILLS}

\section{Abstract}

The hot strip rolling using Steckel Mill has the characteristic profile where the temperature at the head and tail ends is lower when compared to the body and therefore, the rolling load is a lot higher at this region. This paper has the objective of demonstrate the benefits of using the tapering strategy for hot rolling process for thin material using Steckel Mills. We have made a comparison at rolling loads and profile results between after and before the function implementation. At the end of work we have verified that this strategy is essential to roll thin material with Steckel mills.

Keywords: Steckel mill; Tapering; Hot rolling; Rolling loads.

1 Engenheiro Metalúrgico, Mestre em Metalurgia, Assessor Técnico, Laminação de Tiras a Quente, Gerdau Ouro Branco, UFOP e UFMG, Ouro Branco, Minas Gerais, Brasil.

2 Técnico de Processos, Assessor Técnico, Laminação de Tiras a Quente, Gerdau Ouro Branco, Minas Gerais, Brasil;

3 Engenheiro Mecânico, Mestrando em Engenharia de Materiais, Assessor Técnico, Laminação de Tiras a Quente, Gerdau e UFOP, Ouro Branco, Minas Gerais, Brasil.

4 Engenheiro de Automação, Bacharel, Consultor, Siemens VAl, Ostrava, República Tcheca;

5 Engenheiro Metalúrgico, Chefe da Linha de Laminação de Tiras a Quente, Laminação de Tiras a Quente, Gerdau Ouro Branco, Ouro Branco, Minas Gerais, Brasil;

6 Engenheiro Mecânico, Mestre em Metalurgia, Gerente da Linha de Laminação de Tiras a Quente, Gerdau Ouro Branco, UFMG, Ouro Branco, Minas Gerais, Brasil.

* Contribuição técnica ao $51^{\circ}$ Seminário de Laminação - Processos e Produtos Laminados e Revestidos, 28 a 31 de outubro de 2014, Foz do Iguaçu, PR, Brasil. 

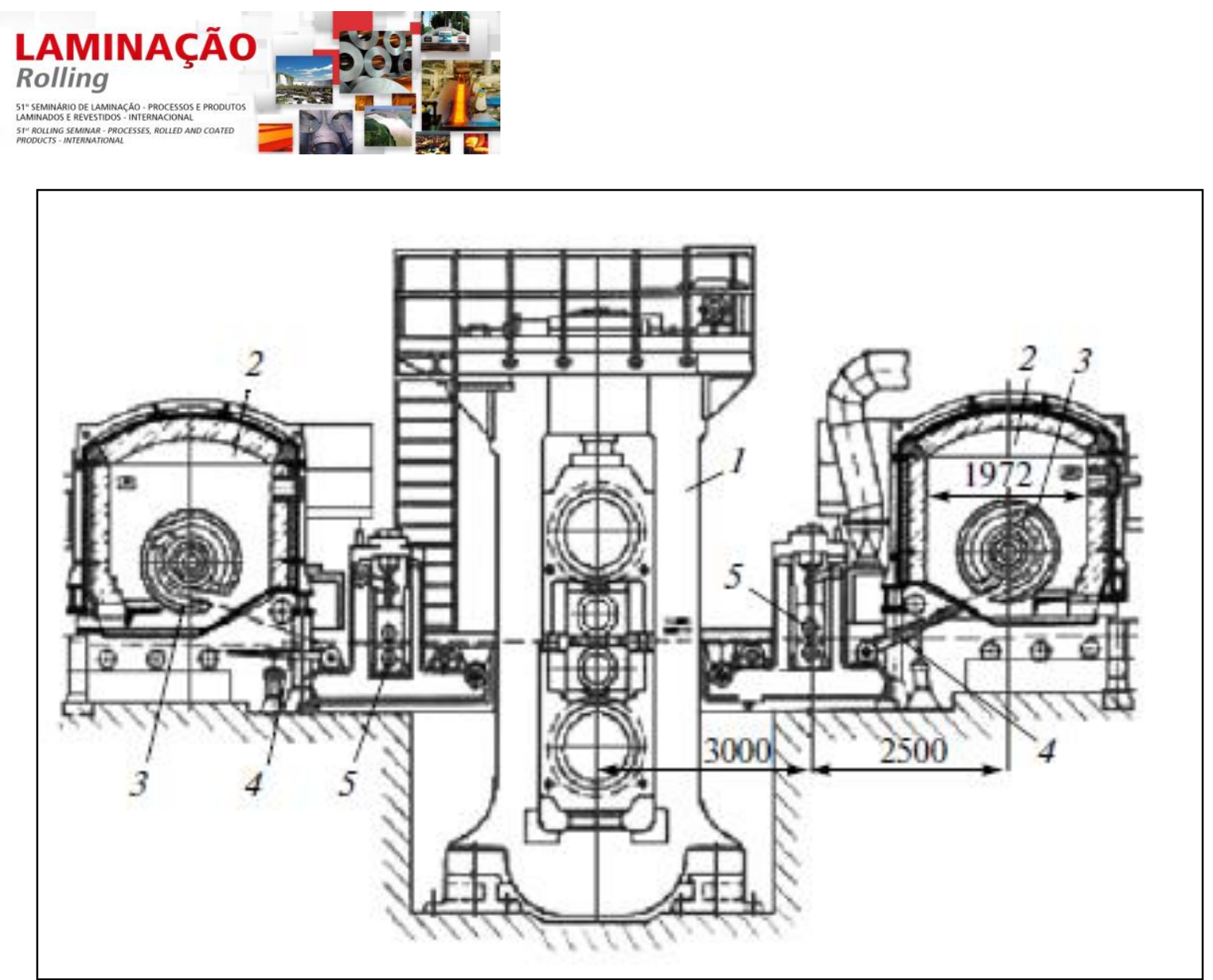

Figura 1. Laminador Quádruo Reversível 1200 de Largura com Fornos Bobinadeira: (1) Cadeira Quáduro; (2) Fornos; (3) Bobinadeiras; (4) Guias; (5) Mesa de Rolos.

O processo no laminador Steckel pode ser descrito em algumas etapas: O material é desbastado e logo após é enviado para a Tesoura de Pontas para eliminar o defeito que geralmente aparece nas pontas do esboço devido ao escoamento irregular do material durante o processo de desbaste, este pode receber um jato de água em alta pressão no processo denominado de Descarepação, onde a carepa (oxidação) é removida por choque térmico e impacto mecânico. Então o material é submetido aos esforços de laminação entre os cilindros de trabalho e é conduzido aos fornos bobinadeiras pelos rolos puxadores e mesas de rolos auxiliares, onde, no momento exato, os sistemas de automação determinam a partida dos dromos para captação da ponta e início do bobinamento do material. Todo este processo de inserção é feito em velocidades relativamente baixas. Ao iniciar o bobinamento todos os equipamentos são acelerados de forma sincronizada para a velocidade ideal de laminação. Quando o passe termina, os equipamentos fazem o posicionamento e se preparam para fazer a mesma sistemática em sentido reverso. Isto se repete até se chegar à espessura desejada, quando o material é enviado para o bobinamento final. O processo de entrada e saída da tira dos dromos e processo de reversão descrito estão ilustrados na Figura 2 [4].

* Contribuição técnica ao $51^{\circ}$ Seminário de Laminação - Processos e Produtos Laminados e Revestidos, 28 a 31 de outubro de 2014, Foz do Iguaçu, PR, Brasil. 

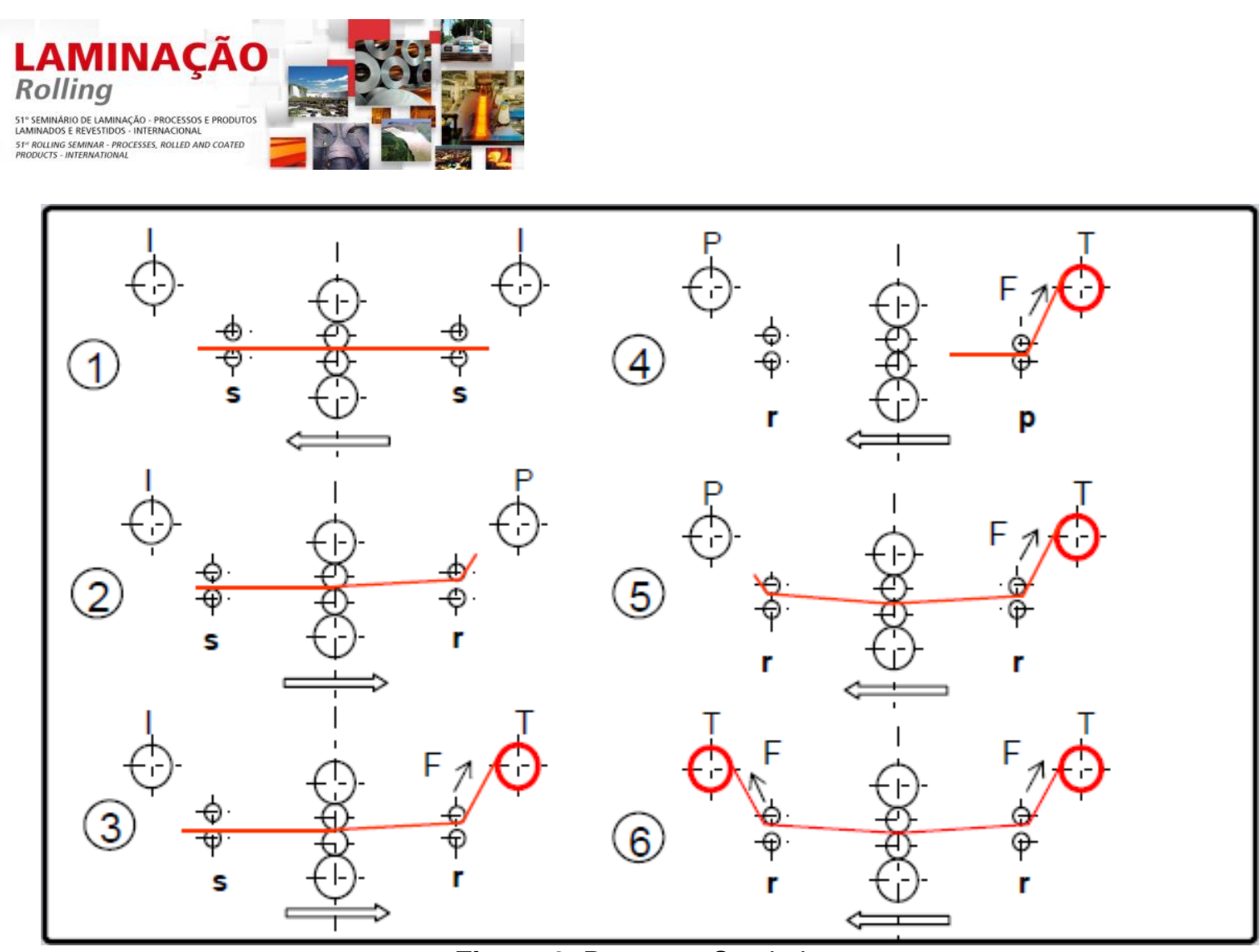

Figura 2. Processo Steckel

Durante cada processo de reversão, na qual envolve paradas, desbobinamento, reversão, e mordidas no laminador, as pontas do material estão sujeitas a um resfriamento maior do que seu corpo. Em decorrência disto ocorre um degrau na temperatura que pode chegar até a $250^{\circ} \mathrm{C}$ em ambas as pontas do material [2]. Com a consequente redução na temperatura, a força de laminação ao longo do comprimento do material aumenta nas pontas. Esta característica é típica em laminadores Steckel, como pode ser observado na Figura 3.

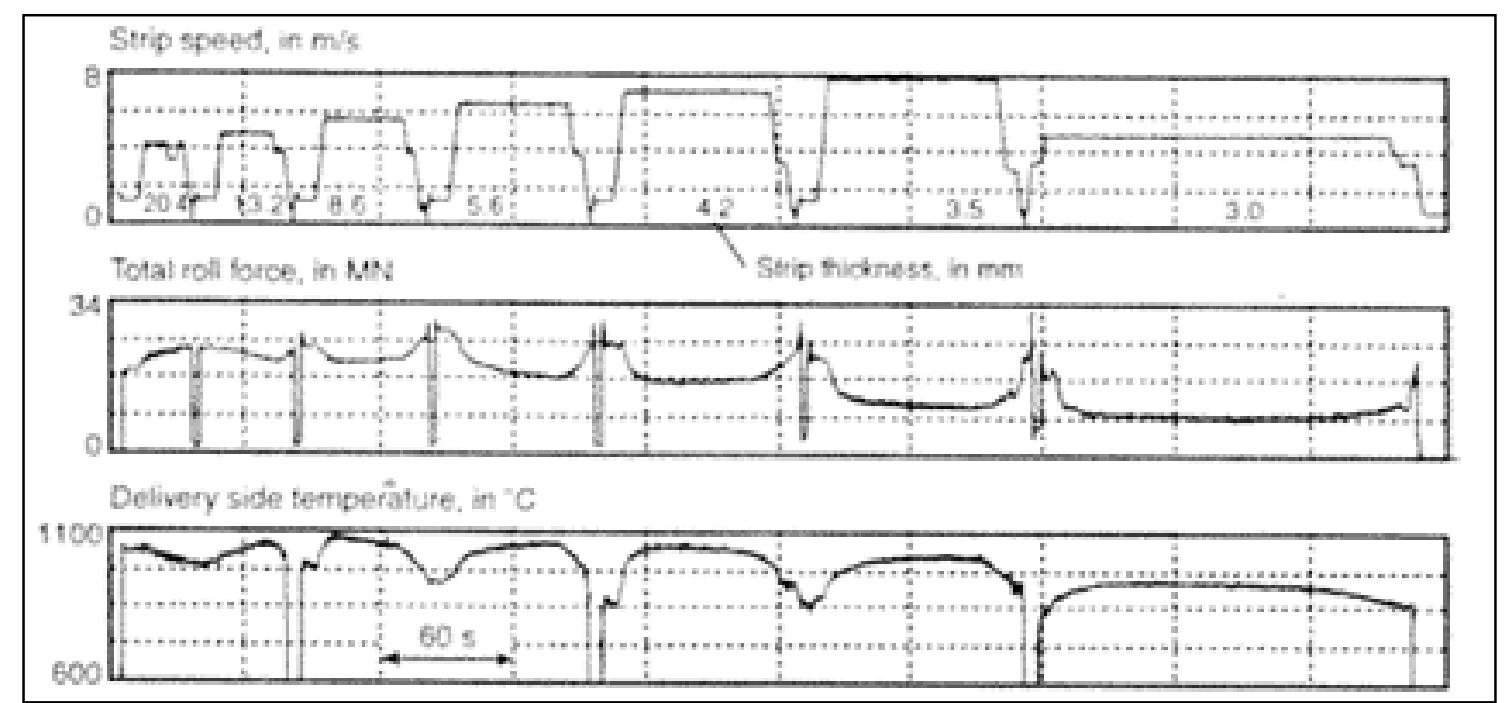

Figura 3. Typical Rolling Record of Strip Temperature and Roll Force of a Steckel Mill

Picos na força de laminação são encontrados devido a um acréscimo na tensão de escoamento a quente na faixa de temperatura que geralmente são atingidas na cabeça e cauda do material, representado na Figura 4. Além do que, o atraso na recristalização devido à redução de temperatura, aumenta significativamente nos últimos passes [2]. Souza [5] afirma que quando a temperatura cai espera-se que a resistência à deformação aumente.

* Contribuição técnica ao $51^{\circ}$ Seminário de Laminação - Processos e Produtos Laminados e Revestidos, 28 a 31 de outubro de 2014, Foz do Iguaçu, PR, Brasil. 


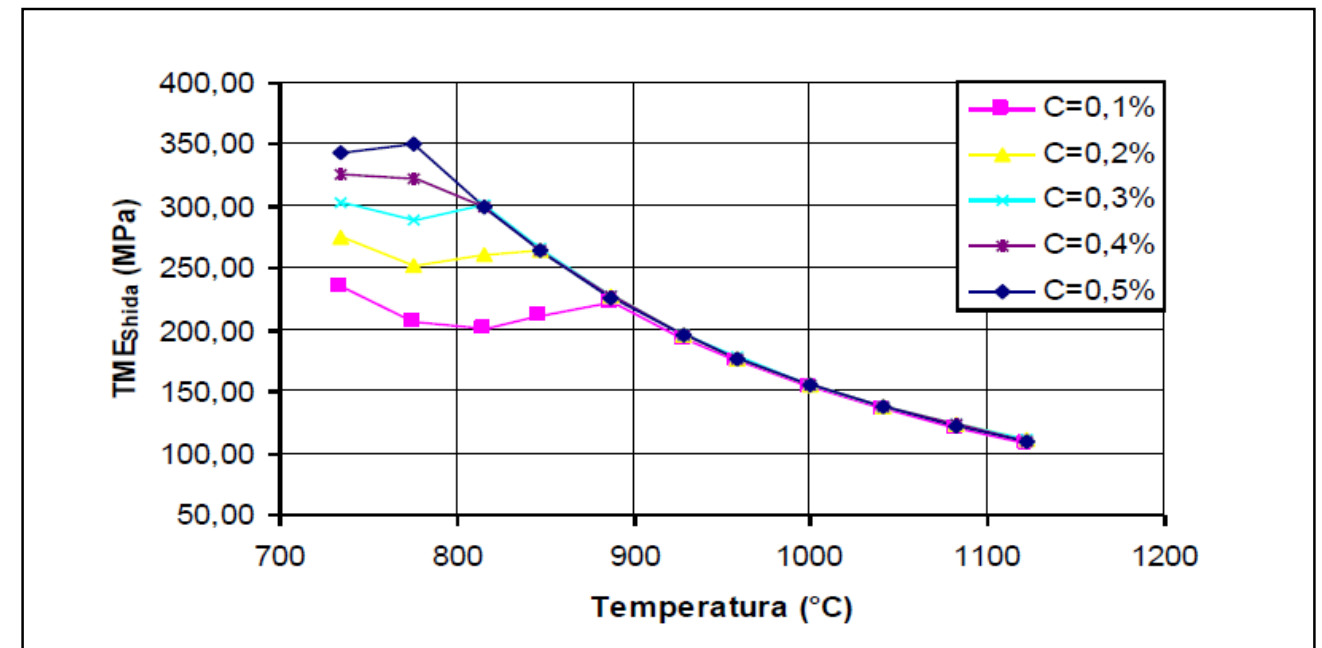

Figura 4. A evolução da TME em função da temperatura para diferentes teores de carbono utilizando a equação de Shida.

Quando se está laminando aços Carbono, a carepa secundária que é formada naturalmente dever ser eliminada com água de descarepação durante cada passe que contribui para perda de temperatura do material. Na medida em que a espessura do passe fica menor o resfriamento é intensificado, principalmente nas pontas.

Para diminuir as quedas de temperatura nas pontas, os motores principais e os equipamentos auxiliares do laminador (ajuste hidráulico da abertura dos rolos, automação, sequência, posicionamento das guias, etc.) devem ser ajustados para permitir uma rápida reversão. Tempos de reversão em torno de quatro segundos podem ser conseguidos configurando assim uma ótima prática. Um exemplo de tempo de reversão é ilustrado na Figura 5 que demonstra o tempo entre passes retirado de dados do processo de laminação.

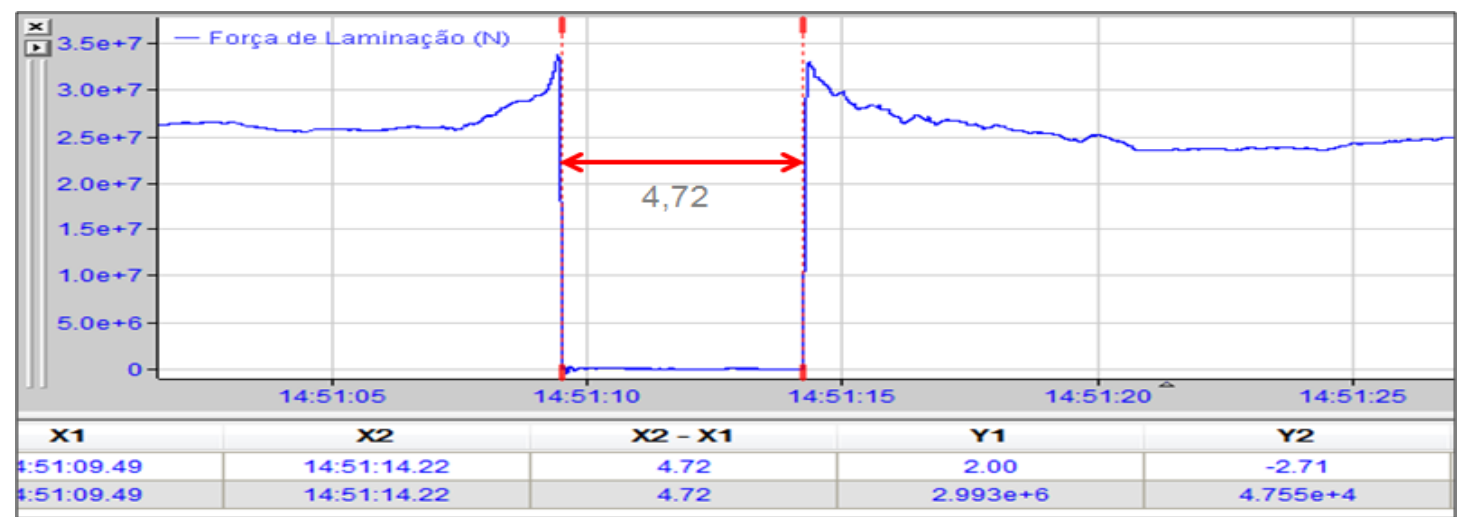

Figura 5. Tempo de Reversão Steckel em 4,72 segundos.

Além de tempos de laminação e reversão menores, práticas de descarepação diferenciadas e bom controle dos fornos do Steckel é utilizada ainda a estratégia de Tapering, para complementar o esforço para diminuição das cargas nas pontas inerentes ao processo durante o último passe de acabamento com consequente melhora nas condições de laminação e planicidade da tira. Esta estratégia consiste na obtenção de um perfil de espessura variável ao longo do comprimento da tira nos passes intermediários fazendo com que as pontas tenham a espessura reduzida ao longo de um comprimento determinado. Como consequência ocorre uma redução da força de laminação nas mesmas para o último passe. A Figura 6 indica uma criação do Tapering com o aumento da redução na cauda do material em a, em b o perfil do

* Contribuição técnica ao $51^{\circ}$ Seminário de Laminação - Processos e Produtos Laminados e Revestidos, 28 a 31 de outubro de 2014, Foz do Iguaçu, PR, Brasil. 


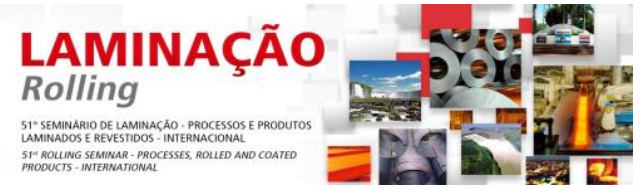

material com Tapering na cauda e em c indica a remoção do Tapering com uma redução menor nessa região.

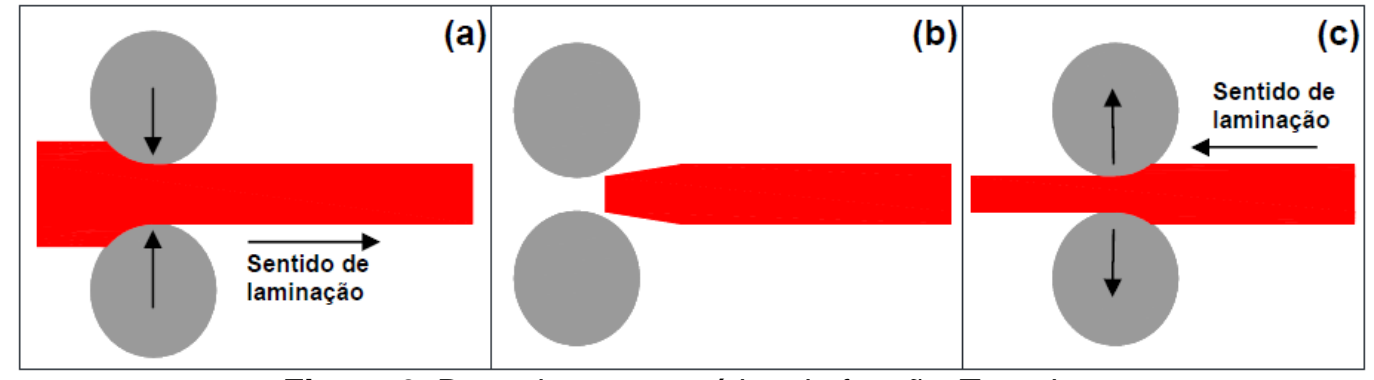

Figura 6. Desenho esquemático da função Tapering.

Dependendo da intensidade do Tapering aplicado a força nas pontas continua mais elevada do que no corpo da tira devido a menor temperatura ou esta diferença pode se tornar nula. Essa redução de força gera uma maior estabilidade no processo e melhoria da forma da tira [5].

\subsection{Laminador de Tiras a Quente da Gerdau}

O novo laminador de tiras a quente da Gerdau possui uma concepção compacta para produção de bobinas a quente. Com 270 metros de comprimento tem capacidade de $823 \mathrm{mil}$ t/ano de bobinas a quente nas espessuras entre 2,0 e $20 \mathrm{~mm}$

e larguras entre 900 e $2100 \mathrm{~mm}$ [7].

A figura 7 apresenta o laminador de tiras a quente da Gerdau esquematicamente. Este é constituído por: (i) um descarepador primário (ii) dois fornos de reaquecimento onde as placas são reaquecidas para a temperatura de laminação (aproximadamente $1200^{\circ} \mathrm{C}$ ); (iii) um laminador Steckel onde ocorrem todos os passes de redução da espessura da placa até a espessura final (desbaste e acabamento); (iv) uma Tesoura Rotativa que faz o corte das pontas irregulares do esboço ao final da etapa de desbaste (espessura de 24 a $39 \mathrm{~mm}$ ); (v) uma mesa de resfriamento com 36 bancos tubulares; (vi) e uma bobinadeira hidráulica [8] e [9].

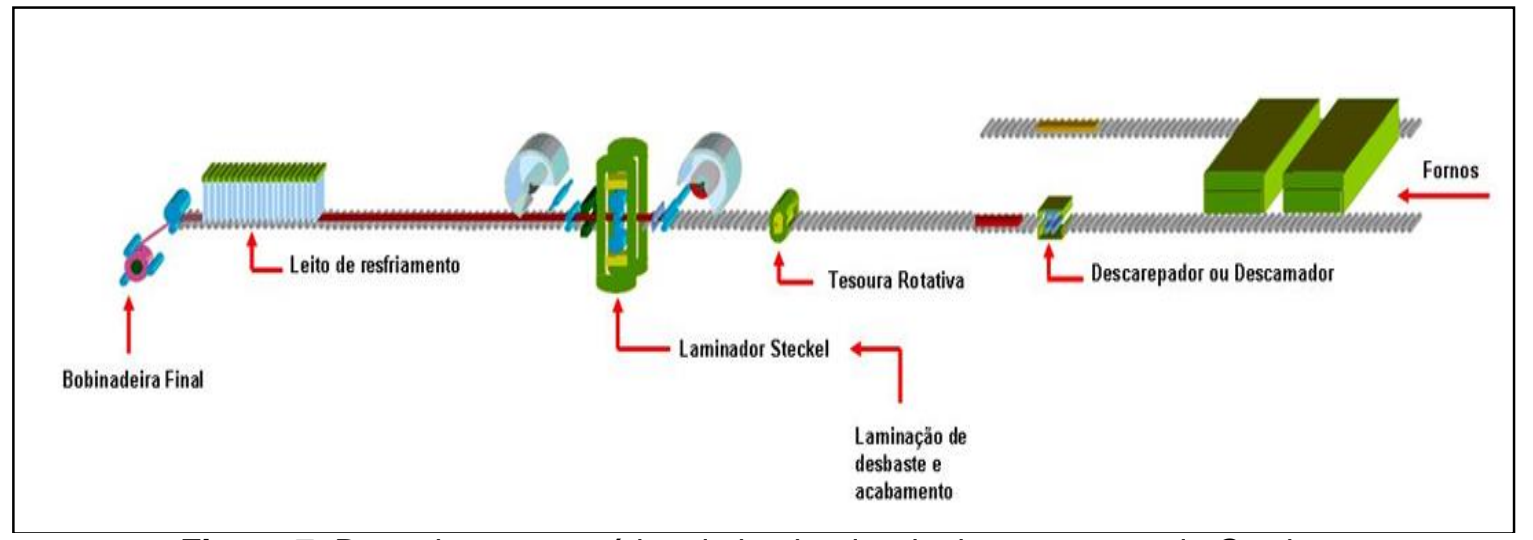

Figura 7. Desenho esquemático do laminador de tiras a quente da Gerdau.

O projeto foi concebido com as mais recentes tecnologias para controle da temperatura, dimensão e forma do laminado. Com respeito ao controle de qualidade, foi instalado um Sistema de Inspeção Superficial Automático para assegurar a qualidade de todas as tiras laminadas.

\section{MATERIAIS E MÉTODOS}

* Contribuição técnica ao $51^{\circ}$ Seminário de Laminação - Processos e Produtos Laminados e Revestidos, 28 a 31 de outubro de 2014, Foz do Iguaçu, PR, Brasil. 
A estratégia de Tapering consiste na obtenção de um perfil de espessura variável ao longo do comprimento da tira laminada nos passes intermediários sendo que as pontas têm a espessura reduzida ao longo de um comprimento determinado.

O modelamento matemático do laminador de tiras a quente da Gerdau fornece os valores de referência para cada passe: posição da abertura de cilindros (GAP), velocidades de laminação, força de laminação e bending, posição do shifting, torque, dimensões nominais da tira, quantidade de água de refrigeração dos cilindros de trabalho, e ganhos dos controles dinâmicos (AGC - Automatic Gauge Control, DPC Dynamic Profile Control) [6]. Este faz os cálculos destas variáveis em múltiplos setpoints ao longo do comprimento do laminado totalizando 20 pontos. O sistema de automação (Nível 1) faz a interpolação dos setpoints recebidos e aplica durante o processamento do material. A disposição dos múltiplos setpoints é demonstrada esquematicamente na Figura 8.

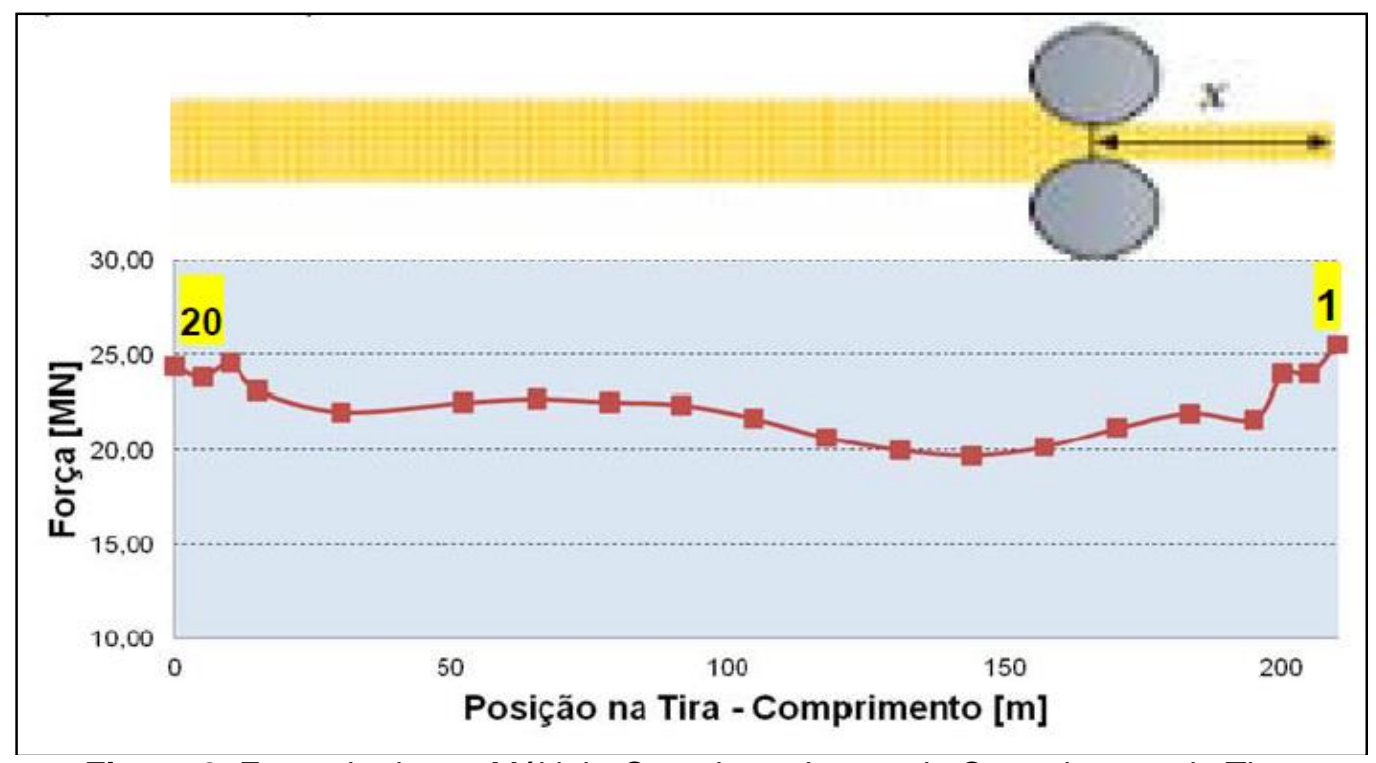

Figura 8. Exemplo de um Múltiplo Setpoint ao Longo do Comprimento da Tira.

Foram selecionadas cinco tiras para a espessura final de $3 \mathrm{~mm}$ na largura de 1200 $\mathrm{mm}$ do material SAE 1012. Para todas as tiras foram executados 8 passes de desbaste e 5 passes de acabamento no Steckel.

A primeira da sequencia foi laminada normalmente sem a utilização do Tapering; na segunda foi aplicado 100 Micra de Tapering no penúltimo passe; na terceira 150 Micra de Tapering. Na quarta foi aplicado 220 Micra de Tapering; e na quinta foi aplicado 300 Micra no penúltimo passe. Em todos os casos o Tapering foi aplicado nos últimos 30 metros. Estão sumarizados na Tabela os procedimentos definidos acima.

Tabela 1 Exemplo de Tapering Aplicado

\begin{tabular}{cc}
\hline Sequência & Tapering $(\mu \mathrm{m})$ \\
\hline Tira 1 & 0 \\
\hline Tira 2 & 100 \\
\hline Tira 3 & 150 \\
\hline Tira 4 & 220 \\
\hline Tira 5 & 300 \\
\hline
\end{tabular}

* Contribuição técnica ao $51^{\circ}$ Seminário de Laminação - Processos e Produtos Laminados e Revestidos, 28 a 31 de outubro de 2014, Foz do Iguaçu, PR, Brasil. 


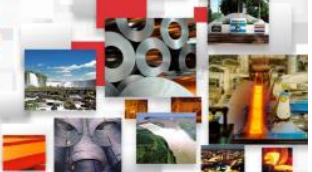

Nos passes anteriores ao penúltimo (3 primeiros) foram aplicados Tapering de forma proporcional com maior profundidade na espessura e em um menor comprimento. A tabela 1 exemplifica o procedimento descrito acima aplicado na Tira 4.

Tabela 2 Exemplo de Tapering Aplicado

\begin{tabular}{cccc}
\hline Número do Passe & Espessura $(\mathrm{mm})$ & Tapering $(\mathrm{mm})$ & Comprimento $(\mathrm{m})$ \\
\hline 1 & 16,17 & 1,16 & 7,7 \\
\hline 2 & 9,12 & 1,22 & 14,1 \\
\hline 3 & 5,88 & 0,58 & 21,5 \\
\hline 4 & 4,09 & 0,22 & 30,2 \\
\hline 5 & 3,00 & & \\
\hline
\end{tabular}

\section{RESULTADOS E DISCUSSÃO}

A distribuição da espessura realizada e calculada para o penúltimo e último passe ao longo do comprimento para o material laminado sem a utilização da estratégia de Tapering (Tira 1) está sendo mostrada na Figura 9.

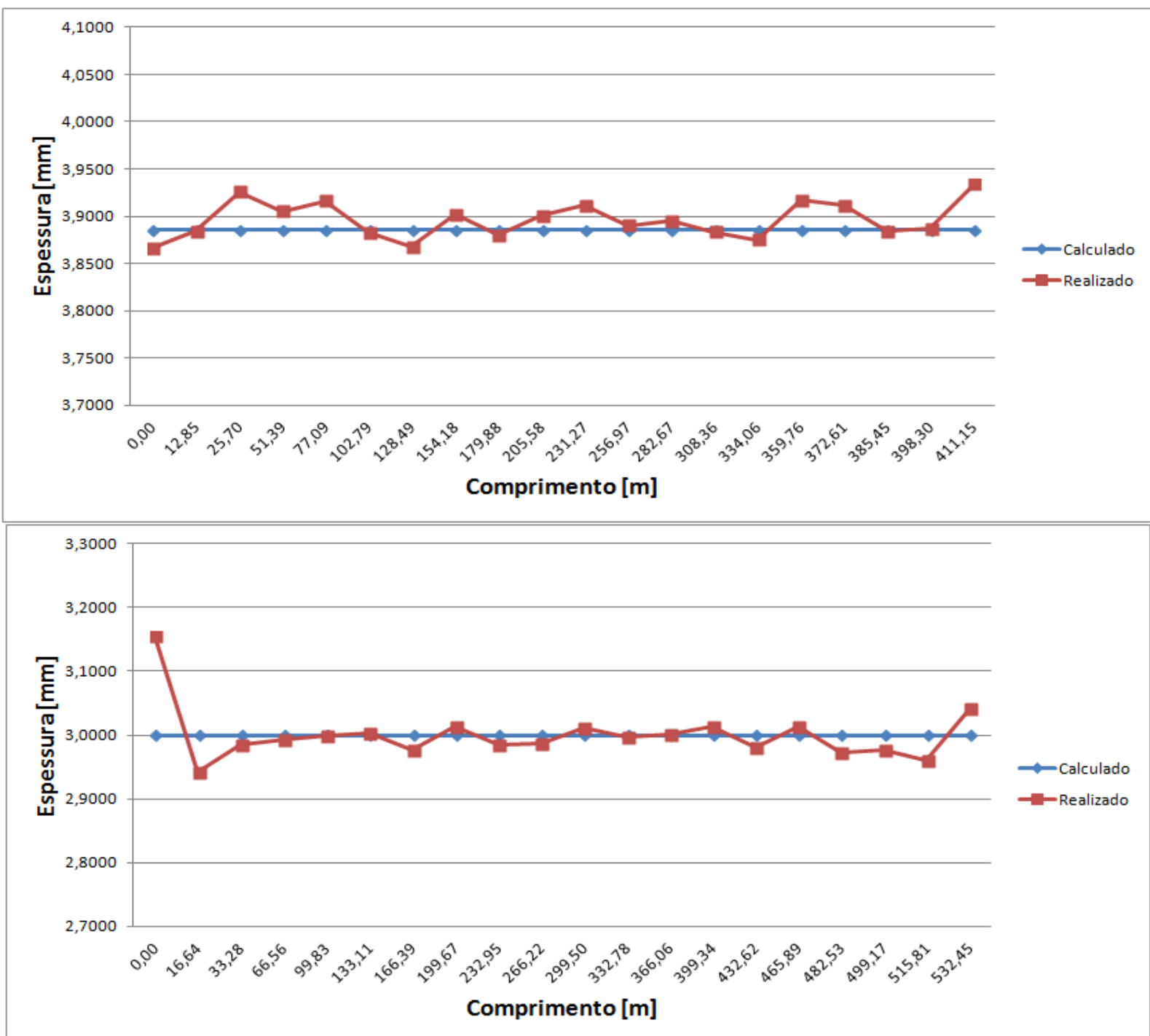

Figura 9. Múltiplos Setpoints do Penúltimo e Último Passe de Laminação do Material sem Tapering Tira 1.

* Contribuição técnica ao $51^{\circ}$ Seminário de Laminação - Processos e Produtos Laminados e Revestidos, 28 a 31 de outubro de 2014, Foz do Iguaçu, PR, Brasil. 


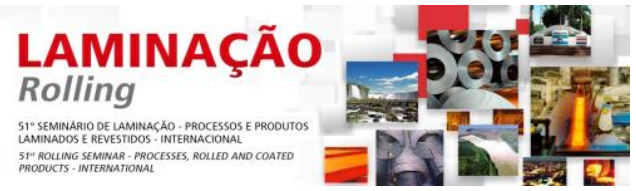

Esta apresentou o perfil de carga característico em laminadores Steckel com maiores cargas nas pontas. O perfil de carga nas pontas do material no fim do penúltimo e início do último estão demonstrados na Figura 10.

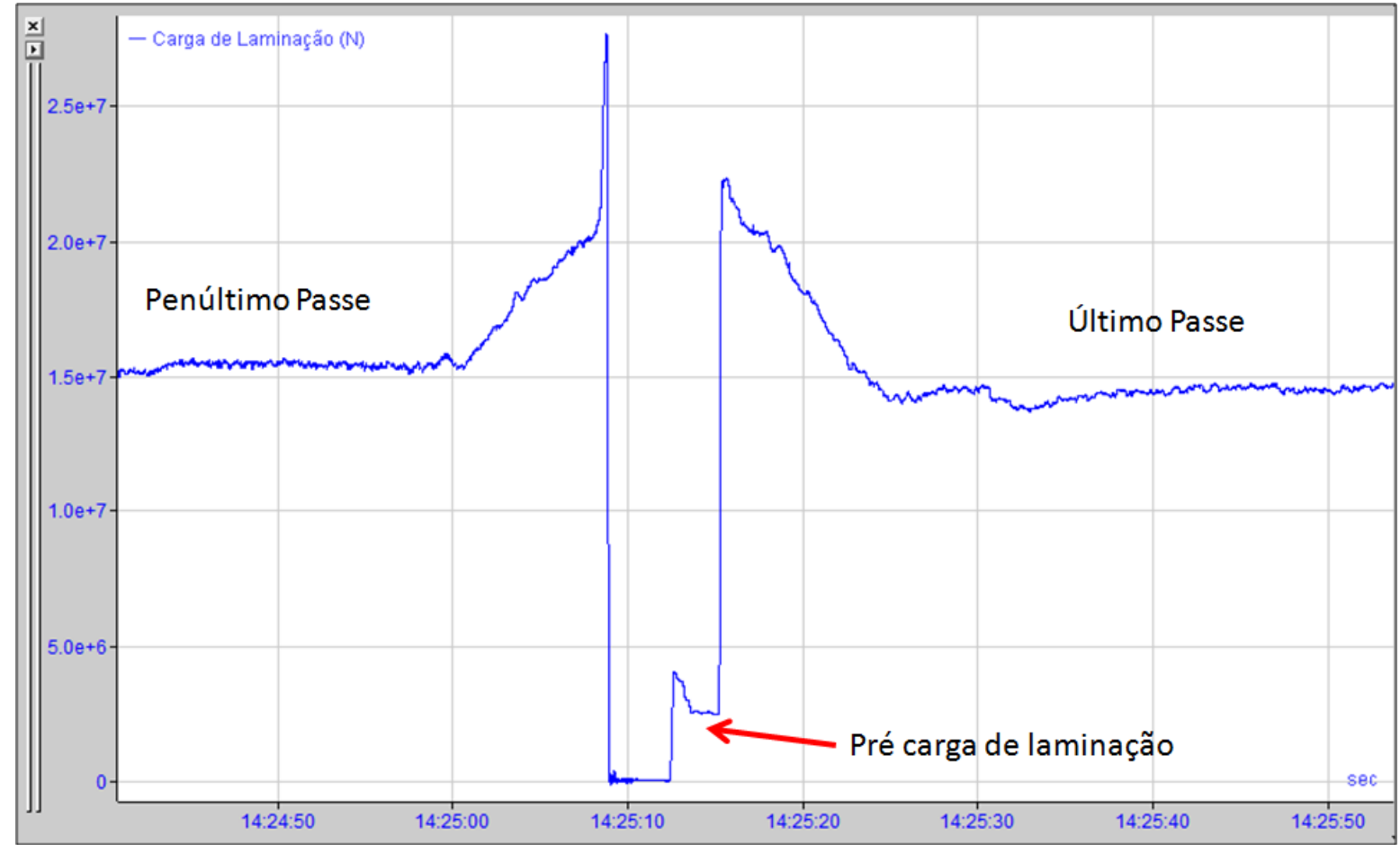

Figura 10. Perfil de Carga na Cabeça do Penúltimo Passe e Último Passe da Tira 1.

Além das cargas mais elevadas nas pontas, pode-se perceber que houve a necessidade de pré-carga de laminação para se alcançar a espessura na cabeça do material.

O perfil de planicidade da Tira 1 está demonstrado na Figura 11. Pode ser observada muita ondulação nas pontas. Isto é devido às maiores cargas aplicadas nesta região e, portanto uma maior deflexão dos cilindros de laminação quando comparado a região do corpo da tira.

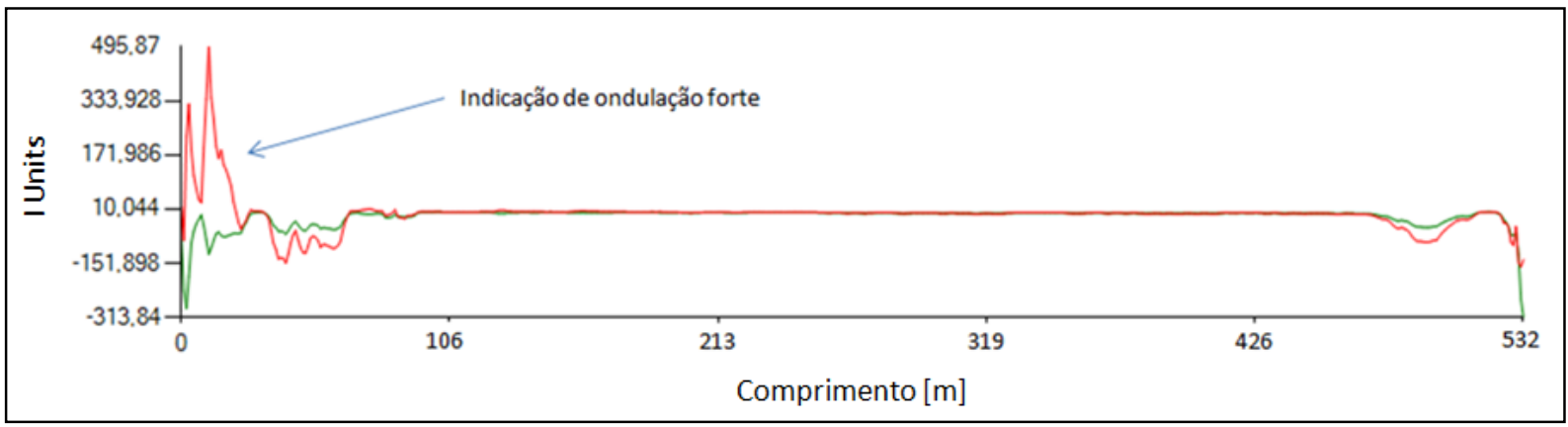

Figura 11. Resultados de Planicidade da Tira 1.

São exibidos a seguir os resultados obtidos com a utilização do Tapering de 300Micra na Tira 5. A distribuição da espessura realizada e calculada para o penúltimo e último passe está sendo mostrada na Figura 12.

* Contribuição técnica ao $51^{\circ}$ Seminário de Laminação - Processos e Produtos Laminados e Revestidos, 28 a 31 de outubro de 2014, Foz do Iguaçu, PR, Brasil. 


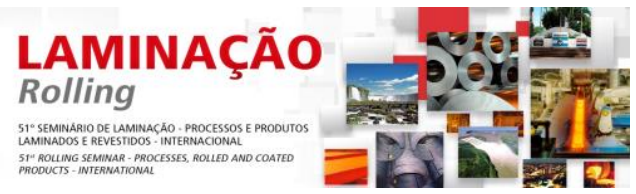

O pico de carga nas pontas do material não foi identificado no último passe e foi atenuado para o penúltimo passe de laminação. A atenuação ocorrida no penúltimo passe foi devido à aplicação do Tapering nos passes inciais do acabamento.

$\mathrm{O}$ resultado de planicidade obtido está demonstrado na Figura 14. Pode se perceber que o material apresentou melhor condição de planicidade com a amplitude máxima de 10 l-Units.

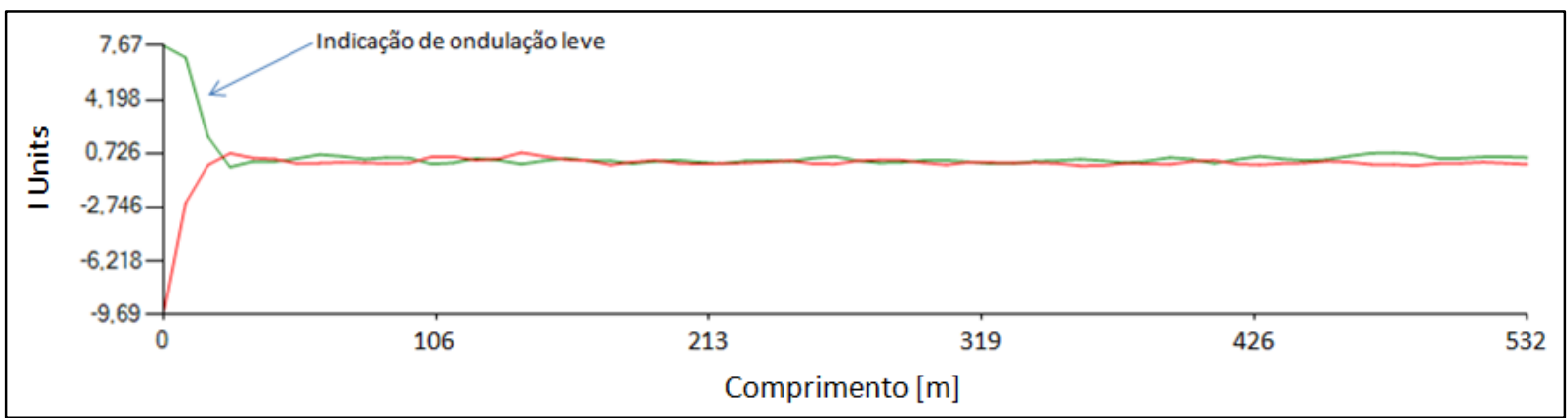

Figura 14. Resultados de Planicidade da Tira 5.

A comparação entre a carga máxima na cabeça e a carga do corpo das cinco tiras, que foram experimentadas em sequencia, está apresentada no gráfico da Figura 15. Podemos observar que a diferença de carga diminui na medida em que foi aumentada a profundidade do Tapering.

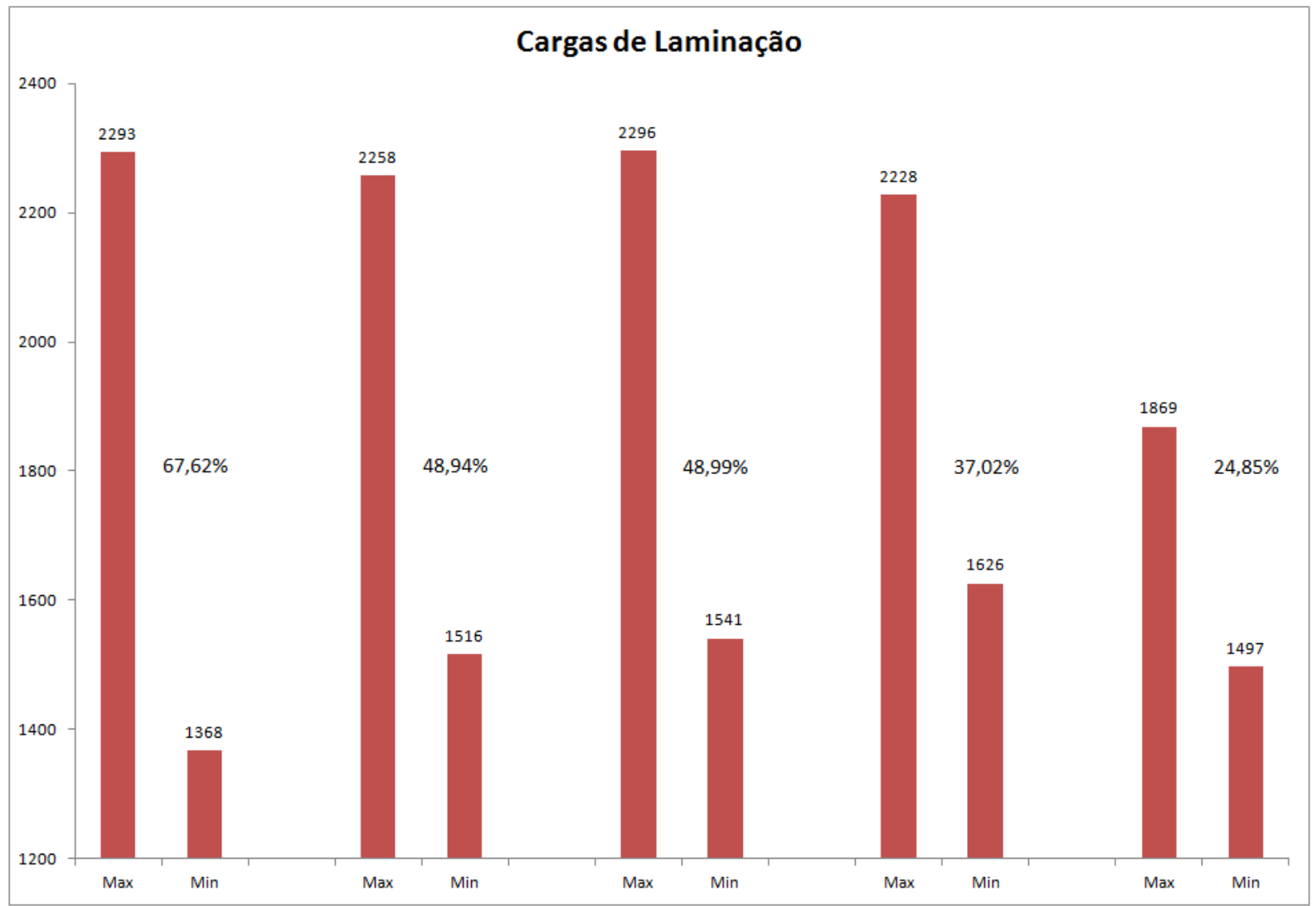

Figura 15. Gráfico Comparativo das Cargas de Laminação entre Cabeça e Corpo.

* Contribuição técnica ao $51^{\circ}$ Seminário de Laminação - Processos e Produtos Laminados e Revestidos, 28 a 31 de outubro de 2014, Foz do Iguaçu, PR, Brasil. 


\section{CONCLUSÃo}

A aplicação desta função apresentou bons resultados para o controle da planicidade do material laminado. A menor variação de carga de laminação entre as pontas do material e o corpo gerou menor necessidade de atuação do sistema Work Roll Bending para correção da deflexão dos cilindros.

Contribuiu também para a estabilidade de laminação de materiais menos espessos, possibilitando assim, a evolução do processamento de aços com maior largura e menor espessura, bem como a laminação de aços com maior resistência mecânica. A aplicação do Tapering é baseada em comprimento e profundidade bem definidos sendo assim necessário que o controle de tracking do material seja apurado possibilitando a aplicação das reduções no momento correto.

A estratégia da aplicação desta função deve ser definida de forma que não gere instabilidade no processamento do aço por ultrapassar os limites de carga nas pontas dos passes anteriores.

\section{Agradecimentos}

A todos os envolvidos no desenvolvimento desta técnica essencial para evolução do mix de produção da Gerdau no portfólio de aços laminados planos.

\section{REFERÊNCIAS}

1 Farmer WiJ. Mr. Steckel and His Mills. International Association of Steckel Mill Operators, 1997.

2 Kramer S, Kneppe G, Rosenthal D. Technology and Performance of Modern Steckel Mills. Iron and Steel Engineer, 1997, p.17-26.

3 Konovalov Yu.V, Khokhlov AS. Benefits of Steckel Mills in Rolling. Steel In Translation, 2013, 43: 206-211.

4 Siemens VAl. Operation Team Training for Gerdau, Sheffield. 2012.

5 Souza AL Estudo da Tensão Média de Escoamento de Aços Laminados em Tiras a Quente. Belo Horizonte: Escola de Engenharia da UFMG; 2010.

6 Souza AL, Reis EG, Silveira JHD, Pereira MM. Modelos Matemáticos da Nova Linha de Laminação de Tiras a Quente da Gerdau. 50 Seminário de Laminação Processos e Produtos Laminados e Revestidos Internacional, 2013, p.274-283.

7 Siemens VAI. Technical Specification for Steckel Mill Plant for GERDAU Ouro Branco. 2010.

8 Souza AL, Borges JM, Schuwarten WJ, Pereira MM, Silveira JHD. Laminação de Tiras a Quente da Gerdau. 50 Seminário de Laminação Processos e Produtos Laminados e Revestidos Internacional, 2013: 369-380.

9 Sandip S, Clark M, Robinson I, Schmidt B. Lastest Development of Plate and Steckel Mill Technologies. $50^{\circ}$ Seminário De Laminação Processos e Produtos Laminados e Revestidos Internacional, 2013, p.803-813. 